\title{
ALTERAÇÕES DERMATOLÓGICAS EM PACIENTES TRANSPLANTADOS PEDIÁTRICOS - CASOS CLÍNICOS E REVISÃO DE LITERATURA
}

\author{
Dermatologic manifestations in pediatric transplant patients - cases report and literature review
}

\author{
Ana Paula Dornelles da Silva Manzoni ${ }^{1}$, Vanessa Santos. Cunha ${ }^{2}$, Ricardo Lapa Kruse ${ }^{3}$, Carina Troian ${ }^{4}$, Tania Ferreira Cestari ${ }^{5}$
}

\begin{abstract}
RESUMO
Introdução: O transplante de órgãos é um exemplo do enorme progresso atingido pela Medicina atual, com os benefícios e problemas inerentes a esse avanço. Muitas dessas conseqüências têm manifestações cutâneas importantes que devem ser bem conhecidas e estudadas. Métodos: Os autores apresentam três casos clínicos de crianças submetidas a transplante de medula óssea, fígado e rim com suas alterações dermatológicas observadas no transcorrer dos seis primeiros meses, ilustrando os diversos aspectos das lesões observadas nesses pacientes, aparados por ampla revisão da literatura. Conclusões: Diante do aumento do número de pacientes transplantados e sua maior perspectiva de vida, muitas são as doenças cutâneas encontradas. Todavia, existe pouco subsídio teórico sobre os achados dermatológicos nos transplantes pediátricos. Desta forma, é fundamental alcançar melhor conhecimento sobre a vasta gama de doenças em prol de sua adequada prevenção e tratamento.
\end{abstract}

Descritores: Pele, Transplante, Crianças, Farmacodermia, Tumores de pele, Doença do enxerto contra hospedeiro, Infecções.

Trabalho realizado no Serviço de Dermatologia do Hospital de Clínicas de Porto Alegre Rua Ramiro Barcellos, 2350 - Porto Alegre - RS.

1. Dermatologista e Pediatra. Mestra pelo Curso de Pós-Graduação em Ciências Médicas: Pediatria da UFRGS

2. Dermatologista e mestra pelo Curso de Pós Graduação UFRGS;

3. Doutorando da Faculdade de Medicina da UFRGS;

4. Doutoranda da Faculdade de Medicina da UFRGS;

5. Professora Adjunto-Doutora de Dermatologia da Faculdade de Medicina da Universidade Federal do Rio Grande do (UFRGS).

Endereço para correspondência: Ana Paula D.S. Manzoni - Rua Afonso Taunay, 180/504 Boa Vista - CEP: 90520-540 - Porto Alegre - RS - Fone/Fax: (51) 3338-7914/2101-8570 E-mail: anamanzoni@terra.com.br

Recebido em: 21.09.2004

Aceito em: 20.01.2005

\section{INTRODUÇÃO}

Os transplantes de órgãos vêm aumentando em número e complexidade. Com as diversas drogas imunossupressoras, novas técnicas cirúrgicas e a sofisticação na assistência ao transplantado, houve um acréscimo significativo na expectativa de vida dos pacientes, principalmente os pediátricos. ${ }^{1}$

Os transplantados possuem risco aumentado de apresentar alterações cutâneas. Estas podem ser decorrentes do uso de múltiplos fármacos, inclusive os imunossupressores, que acrescem o risco de infecções e tumores cutâneos. ${ }^{2}$ Como conseqüência, abriu-se um novo capítulo dermatológico de doenças agudas e crônicas em transplantados.

Neste estudo serão apresentados casos clínicos de transplante de medula óssea, rim e fígado de crianças acompanhadas nos seus seis primeiros meses de transplante, revisando as principais implicações cutâneas presentes nos transplantados pediátricos.

\section{Caso Clínico 1}

Paciente masculino de nove anos de idade, portador de insuficiência renal crônica devido à Síndrome de Alport. No ano de 2003 foi submetido a um transplante renal alogênico de doador cadáver. Ao exame dermatológico, realizado no pós-operatório imediato, apresentava petéquias disseminadas e equimoses no saco escrotal. Após a primeira semana do transplante iniciou com septicemia, sendo tratado com antibióticos de amplo espectro. Logo após, surgiu erupção cutânea de aspecto rendilhado, predominantemente no tronco, compatível com farmacodermia por vancomicina. Com a evolução do quadro, houve necessidade de aumento dos imunossu- 
pressores pelo risco de rejeição do enxerto. A partir deste momento, o paciente apresentou mucosite grau III e alopecia tipo telógena, com importante rarefação capilar. Após a estabilização do quadro clínico infeccioso e do risco de rejeição do enxerto, surgiram lesões no dorso compatíveis com tinha do corpo e onicomadese nos quirodáctilos. No quarto mês do transplante, o paciente compareceu à consulta médica com extenso zoster à altura da $8^{\mathrm{a}}$ vértebra torácica, com áreas necróticas e vésico-bolhas umbilicadas disseminadas na cabeça, tronco e membros (fig.1).

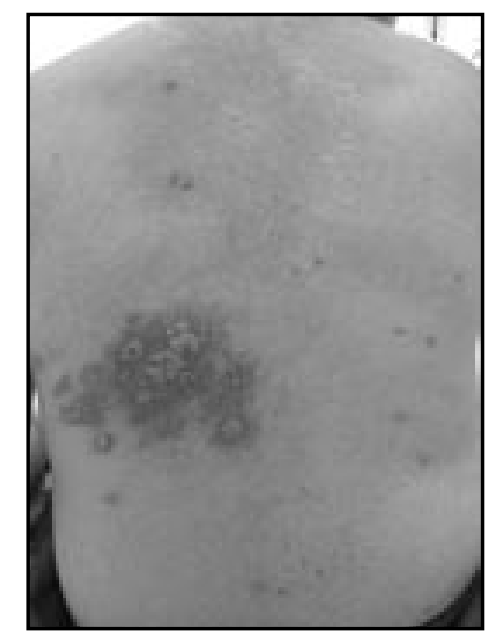

Figura 1: Vésico-bolhas confluente, umbilicadas sobre base eritematosa limitadas na porção média antero-posterior esquerda. Lesões papulosas e vesiculares de aspecto variceliforme disseminadas por todo o tegumento.

\section{Caso Clínico 2}

Paciente masculino de dois anos de idade com diagnóstico de neuroblastoma e falha terapêutica com uso da associação quimioterapia, radioterapia e neurocirurgia. No ano de 2003 foi submetido a transplante de medula óssea (TMO) do tipo autólogo, após indução de aplasia medular com quimioterapia e radioterapia. No período pós-transplante imediato, ao exame dermatológico, apresentava alopecia total do tipo anágena e hipercromia difusa pelos quimioterápicos, mucosite grau II e radiodermite aguda e crônica na região cervical posterior. Após a primeira semana do transplante surgiram petéquias, sufusões hemorrágicas e descamação cutânea do tipo pelagróide nas áreas submetidas à fricção como a região cervical, axila e períneo (fig.2). No primeiro mês de tratamento, iniciou com xerose, queilite labial, prurido e escoriações devido à introdução de isotretinoína como quimioterapia oral. Com dois meses de transplante esteve na consulta médica com dermatite pápulo-erosiva de Jacquet. Durante internação para tratamento de pneumonia, apresentou erupção cutânea por vancomicina.

\section{Caso Clínico 3}

Paciente feminina de dois anos de idade com insuficiência hepática crônica devido a atresia de vias biliares. No ano de 2003 foi submetida a transplante hepático alogênico de doador cadáver. No pós-operatório imediato, apresentava icterícia e petéquias nos membros inferiores. Após o $3^{\circ}$ mês de transplante a paciente iniciou com alopecia areata na região interparietal do couro cabeludo (fig.3).

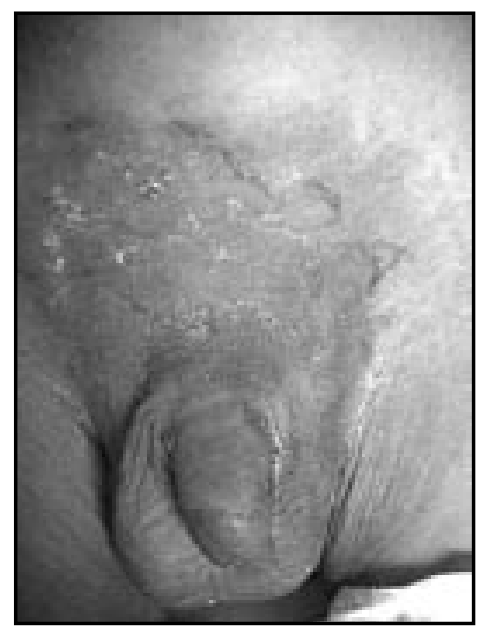

Figura 2: Hipercromia difusa em todo tegumento com descamação de aspecto pelagróide nas áreas de fricção.

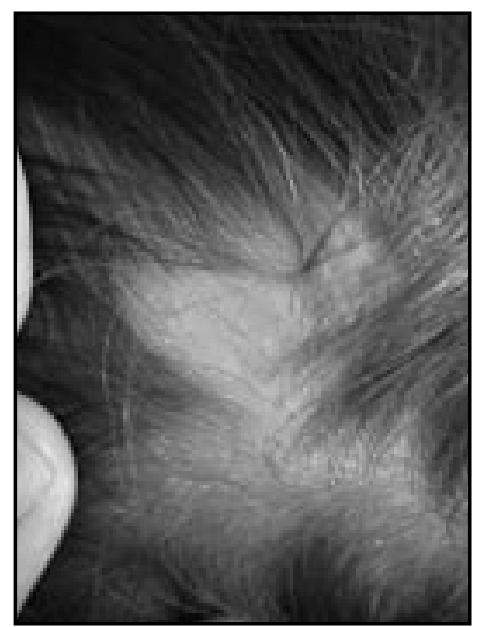

Figura 3: Placa de alopecia areata na região parietal direita com presença de pêlos finos e brancos típicos destas doenças.

\section{DISCUSSÃO}

\section{1) Alterações cutâneas secundárias ao uso de fármacos}

As manifestações dermatológicas decorrentes do uso de medicações variam desde pigmentações ungueais até eritema multiforme maior com suas expressões graves. ${ }^{1,3}$ Os pacientes transplantados, pela multiplicidade de fármacos a que são expostos, estão mais sujeitos a apresentar efeitos-colaterais. O transplantado renal e o de medula óssea acima citados tiveram erupção morbiliforme generalizada secundária ao uso da vancomicina necessária para o controle de septicemia. Esta forma de farmacodermia pode acometer aproximadamente 10\% dos pacientes que utilizam a droga sendo considerado o para-efeito mais freqüente. ${ }^{3,4} \mathrm{~A}$ onicomadese presente no transplantado renal pode ser explicada pelo quadro sistêmico, grave ou secundária ao nível sérico alto de ciclosporina utilizado no controle do processo de rejeição do enxerto. No caso clínico, correspondente ao transplante 
de medula óssea, são identificados os clássicos efeitos colaterais do uso da isotretinoína (xerose e queilite labial). Esta medicação, atualmente, é utilizada como parte da quimioterapia oral pós-transplante de medula óssea em tumores como o Meduloblastoma. ${ }^{4}$ As alterações vasculares descritas podem ser decorrentes da plaquetopenia induzida pelos quimioterápicos pré-TMO, da corticoterapia em altas doses utilizadas no transplantado renal ou das alterações de coagulação secundárias à hepatopatia prévia da transplantada de fígado. ${ }^{4}$ Quanto à gênese da alopecia areata (fig.3), descrita na transplantada de fígado, pode-se aventar que seja secundária ao uso de Tacrolimus ou ao estresse do próprio transplante. ${ }^{3}$ Sabe-se que este tipo de alopecia é bem descrita em hepatopatas e, na sua maioria, melhora após o transplante. Todavia, no caso clínico apresentado, a paciente apresentou seu primeiro episódio após o transplante. ${ }^{4}$ Já o paciente transplantado renal teve alopecia difusa do tipo telógena provavelmente secundária ao quadro sistêmico grave do momento ou pelo uso de imunossupressores como corticóides, azatioprina e tacrolimus para o controle de rejeição do enxerto. ${ }^{5}$ A alopecia universal tipo eflúvio anágeno no paciente transplantado de medula óssea é esperada quando são usados quimioterápicos pré-TMO como ciclofosfamida, etoposide, carmustina e citarabina.,

Os principais antibióticos, antifúngicos, anti-virais e imunossupressores utilizados nos transplantes pediátricos e seus respectivos para-efeitos cutâneos estão apresentados no quadro 1 .

\section{2) Alterações cutâneas secundárias ao condicionamento do TMO}

O transplante de medula óssea é utilizado para reconstruir a função medular. Todos os receptores de medula óssea são submetidos à terapia de condicionamento, cuja finalidade é induzir uma imunossupressão que permita a enxertia das células infundidas e, no caso de doenças neoplásicas, também erradicar o tumor residual do paciente. Para isso, são utilizados quimioterápicos e irradiação corporal. ${ }^{6}$

Os quimioterápicos utilizados pré-TMO, na maioria das vezes, não seriam aplicados caso não houvesse a reposição de medula óssea no transplante, pois podem acarretar danos irreversíveis incompatíveis com a sobrevivência do paciente. A pele apresenta alguns desses para-efeitos como as alterações vasculares e a alopecia tipo eflúvio anágeno já citadas acima. A pigmentação difusa por drogas, como a ciclofosfamida, o etoposide e o busulfan, é facilmente diagnosticada pela equipe médica. Já a pigmentação em áreas de fricção, é causada por quimioterápicos como a carmustina e pode adquirir um aspecto pelagróide causando dúvida diagnóstica já que estes pacientes são submetidos a grande espoliação de vitaminas (fig.2). No quadro 2 estão apresentados os principais quimioterápicos com seus para-efeitos cutâneos. ${ }^{3,4}$

Os pacientes submetidos à radioterapia podem apresentar radiodermites. Na forma aguda, após alguns dias da aplicação, surgem lesões semelhantes à queimadura solar, com edema e eritema que podem evoluir para descamação ou até formar bolhas superficiais, mais acentuadas nas dobras, regiões genitais e lombosacras. É comum que ocorra hiperpigmentação acinzentada que regride sem cicatrizes. Na forma crônica, meses ou anos após a exposição, a pele pode mostrar-se atrófica, com hiperpigmentação, telangectasias e alopecia. ${ }^{2,6} \mathrm{O}$ paciente transplantado de medula óssea foi submetido à radioterapia na região occipital tanto na tentativa de contenção do seu meduloblastoma nos primeiros meses de tratamento quanto para o condicionamento pré-transplante, por isso apresenta manifestações clínicas de radiodermite aguda e crônica concomitantemente.
A grande maioria dos pacientes com TMO apresenta mucosite no trato gastrointestinal. A quimioterapia em $40 \%$ e a radioterapia de cabeça e pescoço em $80 \%$ determinam o seu desenvolvimento. ${ }^{6,7,8}$ Os quimioterápicos mais comumente associados à mucosite são a bleomicina, a dactinomicina, a daunorubicina, o docetaxel, a doxorubicina, o edatrexate, o fluoracil, o metotrexate, o tomudex e o topotecan. O diagnóstico de mucosite é clínico, iniciando com dor, edema e eritema na mucosa oral. Posteriormente surgem erosões e ulcerações, causando intensa dificuldade na alimentação. ${ }^{6,8}$ Menos comumente, a mucosite pode ser vista secundária a outras causas de imunossupressão, como foi apresentado no transplantado renal.

\section{3) Alterações cutâneas secundárias à Doença do Enxerto contra o Hospedeiro (DECH)}

A DECH é uma síndrome grave caracterizada por alterações hepáticas, intestinais e cutâneas. Ela é observada, fundamentalmente, após transplante alogênico de medula óssea e, com uma freqüência bem menor, após transplantes autólogos, transfusões sangüíneas e transplantes de órgãos sólidos como fígado e pulmão. ${ }^{8,9} \mathrm{O}$ risco de DECH nos TMO alogênicos HLA-compatíveis é de 40 a 50\% e nos singênicos (entre gêmeos) é de 5 a $30 \% .^{9}$ Pacientes com doadores relacionados têm uma probabilidade em torno de $20 \%$ de desenvolver a doença, enquanto que nos receptores de doadores não relacionados a chance é de até $80 \%$. A DECH incide em cerca de $13 \%$ das crianças com TMO antes dos 10 anos de idade e em $30 \%$ daquelas entre os 10 e 19 anos. $^{9}$ A forma aguda manifesta-se a partir da "pega" do enxerto, podendo ocorrer, por definição, até o 100o dia pós-transplante e caracteriza-se, na sua maioria, por lesões máculo-papulosas nas regiões palmo-plantares, tronco, pavilhões auriculares e peri-ungueais. ${ }^{8,9} \mathrm{~A}$ forma crônica da DECH ocorre, por definição, após o $100^{\circ}$ dia do TMO e, na pele, assume aspecto liquenóide ou esclerodermiforme, principalmente. A pele é afetada em 90 a 100\% dos pacientes com DECH crônica. O tipo liquenóide caracteriza-se por pápulas liquenóides, violáceas, assintomáticas ou ligeiramente pruriginosas localizadas mais na região periorbitária, nas orelhas e nas extremidades. A forma esclerodermiforme é mais rara e tardia. Apresenta-se principalmente no tronco, nádega e coxas, através de placas endurecidas e não pregueáveis que podem coalescer. ${ }^{8}$ Muitas vezes o diagnóstico da DECH é difícil sendo importante verificar a ocorrência de alterações hepáticas e de diarréia para selar a principal tríade diagnóstica da síndrome..$^{6,8,9}$

\section{4) Alterações cutâneas secundárias à presença de infecções}

$\mathrm{O}$ estado de imunossupressão leva a um aumento significativo do número e da gravidade das infecções, além da ocorrência de manifestações atípicas. ${ }^{1}$ Ao mesmo tempo, os transplantados são pacientes de alta complexidade e exigem internações hospitalares freqüentes que os colocam em contato com microorganismos nosocomiais muitas vezes resistentes às terapêuticas utilizadas. As infecções foram o segundo achado cutâneo mais freqüentemente encontrado em crianças transplantadas de $\operatorname{rim}(70 \%){ }^{2}$

As infecções fúngicas estão bastante associadas à morbi-mortalidade dos transplantados. ${ }^{10}$ Sua prevalência varia conforme o tipo de transplante (5\% dos transplantes de rim até $50 \%$ dos transplantes de fígado). A maioria destas infecções ocorre nos primeiros 180 dias pós-transplante. ${ }^{11}$ Este fato foi evidenciado no caso 1 que apresentou tinha do corpo próximo ao $90^{\circ}$ dia de transplante. As infecções fúngicas mais comumente encontradas são: 
Quadro 1: Principais alterações cutâneas secundárias a medicações antiinfecciosas e imunossupressores usados por pacientes transplantados pediátricos*

\begin{tabular}{|c|c|}
\hline \multicolumn{2}{|r|}{ ANTIBIÓTICOS } \\
\hline Amicacina & Exantema $(3,7 \%)$ e prurido. \\
\hline Ampicilina & $\begin{array}{l}\text { Exantema }(>10 \%) \text {, reação alérgica cutânea } \\
(1-10 \%) \text {, prurido }(1-5 \%) \text {, eritema multiforme } \\
(<1 \%) \text {, erupções bolhosas }(1 \%) \text {. Outros: } \\
\text { dermatite de contato, pustulose exantematosa } \\
\text { generalizada aguda. }\end{array}$ \\
\hline $\begin{array}{c}\text { Cefalosporinas } \\
\text { Cefepime }\end{array}$ & $\begin{array}{l}\text { Exantema (1-10\%), prurido (1-5\%). Outros: } \\
\text { urticária, angioedema, eritema multiforme. } \\
\text { a) Erupção maculosa ( } 51 \%) \text {, prurido (1-10\%), } \\
\text { urticária }(1.8 \%) \text { e exantemas (1.8\%). Outras: } \\
\text { necrólise epidérmica tóxica, síndrome de } \\
\text { Stevens-Johnson. } \\
\text { b) Angioedema ( } 2 \%) \text {, eritema multiforme }(2 \%) \text {, } \\
\text { prurido ( } 2 \%) \text {, exantema ( } 2 \%) \text { e necrólise } \\
\text { epidérmica tóxica ( } 2 \%) \text {. Outros: pênfigo } \\
\text { eritematoso, eritema tóxico, pustuloderma tóxico. }\end{array}$ \\
\hline Ciprofloxacina & $\begin{array}{l}\text { Erupção maculosa }(1-10 \%) \text {, angioedema }(<1 \%) \text {, } \\
\text { eritrodermia }(<1 \%) \text {, dermatite esfoliativa }(<1 \%) \text {, } \\
\text { hiperpigmentação }(<1 \%) \text {, fotossensibilidade } \\
(<1 \%) \text {, prurido }(<1 \%) \text {, vasculite }(<1 \%) \text { e necrólise } \\
\text { epidérmica crônica }(<1 \%) \text {. Outros: eritema } \\
\text { anular centrífugo, lúpus eritematoso, psoríase, } \\
\text { síndrome de Stevens-Johnson, urticária, } \\
\text { vasculite, dermatite esfoliativa. }\end{array}$ \\
\hline Imipenem & $\begin{array}{l}\text { Erupção maculosa ( } 4 \%) \text {, reações alérgicas } \\
\text { cutâneas }(1-3 \%) \text { e prurido }(0,3 \%) \text {. Outras: } \\
\text { necrólise epidérmica tóxica, flushing, diaforese, } \\
\text { candidose, urticária, eritema multiforme. }\end{array}$ \\
\hline Metronidazol & $\begin{array}{l}\text { Prurido (1-5\%). Outros: urticária, flushing, } \\
\text { exantema, pustulose exantematosa aguda } \\
\text { generalizada. }\end{array}$ \\
\hline Piperacilina & $\begin{array}{l}\text { Reações alérgicas cutâneas }(2-4 \%) \text {, erupção } \\
\text { maculosa (1\%) e reação de Jarisch-Herxheimer } \\
\text { (<1\%). Outros: exantema, urticária, síndrome de } \\
\text { Stevens-Johnson, necrólise epidérmica tóxica. }\end{array}$ \\
\hline Vancomicina & $\begin{array}{l}\text { Calafrios, erupção eritematosa ( }>10 \%) \text {, rubor } \\
(1-10 \%) \text {, eritema grave }(1-10 \%) \text {, angioedema } \\
(1-10 \%) \text {, síndrome de Stevens-Johnson }(<1 \%) \\
\text { e vasculite }(<1 \%) \text {. Outros: necrólise epidérmica } \\
\text { tóxica, urticária, exantema, eritema multiforme, } \\
\text { pustulose exantematosa aguda generalizada, } \\
\text { lúpus eritematoso, erupções bolhosas, dermatite } \\
\text { esfoliativa, prurido. }\end{array}$ \\
\hline \multicolumn{2}{|r|}{ ANTIVIRAIS } \\
\hline Aciclovir & $\begin{array}{l}\text { Prurido (1-10\%), exantema }(1-5 \%) \text { e acne }(<3 \%) \text {. } \\
\text { Outros: dermatite de contato, edema periférico, } \\
\text { síndrome de Stevens-Johnson. }\end{array}$ \\
\hline
\end{tabular}

\begin{tabular}{|c|c|}
\hline Ganciclovir & $\begin{array}{l}\text { Erupção maculosa }(<10 \%) \text {, prurido }(<5 \%) \text {, flebite } \\
(<2 \%) \text {, acne }(<1 \%) \text {, erupção bolhosa }(<1 \%) \text {, } \\
\text { edema }(<1 \%) \text {, erupção fixa }(<1 \%) \text {, edema facial } \\
(<1 \%) \text {, fotossensibilidade }(<1 \%) \text {, alopécia }(<1 \%) \text {, } \\
\text { pigmentação }(<1 \%) \text {, urticária }(<1 \%) \text {. Outros: } \\
\text { psoríase, púrpura, síndrome de Stevens-Johnson, } \\
\text { hiperplasia gengival, calafrios, dermatite esfoliativa. }\end{array}$ \\
\hline Foscarnet & $\begin{array}{l}\text { Pigmentação (>5\%), diaforese }(>5 \%) \text {, exantema } \\
(>5 \%) \text {, flushing }(>5 \%) \text {, edema facial }(>5 \%), \\
\text { estomatite ulcerativa }(>5 \%) \text {, prurido }(>5 \%), \\
\text { dermatite seborréica }(>5 \%) \text {, ulcerações }(>5 \%) \text {, } \\
\text { psoríase }(<1 \%) \text {, alopécia }(<1 \%) \text {, edema }(<1 \%), \\
\text { herpes simples }(<1 \%) \text {, edema nas pernas }(<1 \%) \text {. } \\
\text { Outros: necrólise epidérmica tóxica, úlceras } \\
\text { perineais, leucoplasia oral, exantema. }\end{array}$ \\
\hline \multicolumn{2}{|r|}{ ANTIFÚNGICOS } \\
\hline Anfotericina B & $\begin{array}{l}\text { Flushing }(1-10 \%) \text {, exantema }(<1 \%) \text {. Outras: } \\
\text { púrpura, prurido, fenômeno de Raynaud. }\end{array}$ \\
\hline Fluconazol & $\begin{array}{l}\text { Exantema }(1,8 \%) \text { e palidez }(<1 \%) \text {. Outras: } \\
\text { necrólise epidérmica tóxica, angioedema, prurido, } \\
\text { eritema multiforme. }\end{array}$ \\
\hline \multicolumn{2}{|r|}{ IMUNOSSUPRESSORES } \\
\hline Corticoide & $\begin{array}{l}\text { Estrias, face cushingóide, hipertricose, púrpuras, } \\
\text { telangectasias, alopecia, acne, tumores cutâneos } \\
\text { não melanoma. }\end{array}$ \\
\hline Ciclosporina & $\begin{array}{l}\text { Hiperplasia gengival, alopecia, hipertricose, } \\
\text { reação anafilática, edema de face e } \\
\text { extremidades, cistos epidérmicos, foliculite, } \\
\text { hidradenite, onicopatia, hiperplasia sebácea, } \\
\text { urticária. ulcerações orais, surgimento de cristas } \\
\text { transversais nas unhas, pigmentação cutânea } \\
\text { aumentada, alterações tromboembólicas. }\end{array}$ \\
\hline Tacrolimus & $\begin{array}{l}\text { Hiperplasia gengival (menos significativa que a } \\
\text { Ciclosporina), alopecia (mais significativo que } \\
\text { ciclosporina), púrpura trombocitopênica }\end{array}$ \\
\hline Azatioprina & $\begin{array}{l}\text { Acne, alopecia, angioedema, úlceras orais, } \\
\text { eritema localizado, erupções cutâneas, } \\
\text { principalmente máculo-papulosas. }\end{array}$ \\
\hline $\begin{array}{l}\text { Micofenolato } \\
\text { mofetil }\end{array}$ & $\begin{array}{l}\text { Acne, edema facial e de extremidades, úlceras } \\
\text { orais, púrpura trombocitopênica, prurido, } \\
\text { erupções acneiformes e morbiliformes, flebite } \\
\text { causada pelo extravasamento cutâneo quando } \\
\text { utilizado por via parenteral. }\end{array}$ \\
\hline $\begin{array}{c}\text { Sirolimus } \\
\text { (Rapamicina) }\end{array}$ & $\begin{array}{l}\text { Síndrome do cabelo quebradiço, púrpura } \\
\text { trombocitopênica, erupções acneiformes, } \\
\text { exantemas, prurido, hipertrofia cutânea, ulcerações, } \\
\text { equimose, celulite, hirsutismo e edema facial. }\end{array}$ \\
\hline $\begin{array}{l}\text { Muromonab } \\
\text { CD3 (OKT3): }\end{array}$ & Erupções morbiliformes generalizadas e prurido. \\
\hline
\end{tabular}




\section{a. Candidoses}

Leveduras do gênero Candida $s p$, causam as infecções fúngicas mais freqüentes dos transplantados. ${ }^{1,11}$ A forma mucocutânea é a mais freqüente. Quando se torna sistêmica, o comprometimento cutâneo está presente em 5 a 10\% dos pacientes através de máculas ou pápulas eritematosas que podem tornar-se purpúricas, ulceradas

Quadro 2: Quimioterápicos comumente usados no condicionamento do transplante pediátricos de medula óssea e seus principais efeitos colaterais cutâneos*

\begin{tabular}{|c|c|}
\hline Busulfan & $\begin{array}{l}\text { Urticária, eritema e alopécia ( }>10 \%) \text {, } \\
\text { pigmentação cutânea e ungueal }(1-10 \%) \text {. } \\
\text { Outras: vasculite, exantema, queilite, eritema } \\
\text { nodoso, eritema multiforme, siringometaplasia } \\
\text { escamosa écrina, dermatite esfoliativa, } \\
\text { porfiria cutânea tarda. }\end{array}$ \\
\hline Carmustina & $\begin{array}{l}\text { Alopécia e flushing (1-10\%), dermatites }(<1 \%) \text {. } \\
\text { Outras: dermatite de contato, pigmentação e } \\
\text { irritação local (por contato), telangectasias, } \\
\text { siringometaplasia escamosa écrina. }\end{array}$ \\
\hline Ciclofosfamida & $\begin{array}{l}\text { Alopécia e erupção cutânea (1-10\%), flushing } \\
(1-10 \%) \text {, necrólise epidérmica tóxica }(<1 \%) \text {, } \\
\text { pigmentação cutânea e ungueal }(<1 \%), \\
\text { eritema multiforme }(<1 \%) \text {. Outras: carcinoma } \\
\text { epidermóide, urticária, síndrome de Stevens- } \\
\text { Johnson, linfoma, eritema acral, irritação local } \\
\text { por extravasamento, vasculite, hidradenite } \\
\text { neutrofilica écrina, siringometaplasia } \\
\text { escamosa écrina, porfiria cutânea tarda e } \\
\text { intermitente aguda, dermatite herpetiforme, } \\
\text { dermatite por recuperação de linfócitos, } \\
\text { discromia no cabelo }\end{array}$ \\
\hline Citarabina & $\begin{array}{l}\text { Alopécia e erupção cutânea (>10\%), prurido, } \\
\text { alopécia e sardas ( } 1-10 \%) \text {. Outras: eritema } \\
\text { acral, síndrome de eritrodisestesia acral, } \\
\text { ceratose seborréica, hidradenite neutrofílica } \\
\text { écrina, vasculite, exantema, ceratose actínica } \\
\text { e seborréica, necrólise epidérmica tóxica, } \\
\text { siringometaplasia escamosa écrina. }\end{array}$ \\
\hline Etoposide & $\begin{array}{l}\text { Alopecia (8-66\%), reação alérgica cutânea } \\
(1-2 \%) \text { e flushing (<1\%). Outras: exantema, } \\
\text { síndrome de Stevens-Johnson, eritema, } \\
\text { irritação local por extravasamento, } \\
\text { pigmentação cutânea e ungueal, eritema acral, } \\
\text { urticária, siringometaplasia escamosa écrina, } \\
\text { dermatite por recuperação de linfócitos. }\end{array}$ \\
\hline Melfalan & $\begin{array}{l}\text { Prurido, erupção maculosa, alopécia, } \\
\text { vasculite e vesiculação (1-10\%). Outras: } \\
\text { urticária, exantema, angioedema, irritação } \\
\text { local por extravasamento, pigmentação } \\
\text { ungueal, eritema acral. }\end{array}$ \\
\hline Isotretinoína & $\begin{array}{l}\text { Reações cutâneas alérgicas, púrpura, } \\
\text { acne fulminante, alopecia, equimose, } \\
\text { queilite, xerose, epistaxe, xantoma eruptivo, } \\
\text { fragilidade cutânea, alterações do cabelo, } \\
\text { hirsutismo, hiper ou hipopigmentação, } \\
\text { descamação palmo-plantar, reações } \\
\text { fotoalérgicas, prurido, erupção morbiliforme, } \\
\text { distrofia ungueal, paroníquia, eritema facial, } \\
\text { queimadura solar, diaforese, dermatite } \\
\text { seborréica, eczema, urticária. }\end{array}$ \\
\hline
\end{tabular}

ou necróticas. ${ }^{2}$ As espécies mais encontradas são Candida albicans (70\%), C. glabrata (8\%), C. tropicalis $(6,9 \%)$, C. parapsilosis $(1,9 \%)$, e C. Krusei $(1,7 \%){ }^{11}$

\section{b. Dermatofitoses}

São determinadas pelos mesmos gêneros de fungos causadores de infecções em indivíduos imunocompetentes: Microsporum, Trichophyton e Epidermophyton. ${ }^{11}$ Todavia, os imunossuprimidos tendem a apresentar formas mais exuberantes. ${ }^{10}$ A onicomicose branca proximal é própria dos pacientes imunocomprometidos, sendo o Trichophyton rubrum o seu causador mais comum. ${ }^{12}$

\section{c. Pitiríase versicolor}

A imunossupressão é fator predisponente da pitiríase versicolor e podem afetar $14,5 \%$ dos transplantados pediátricos de órgãos sólidos. ${ }^{2}$ A manifestação clínica tende a ser mais exuberante e apresentar-se também em locais atípicos. ${ }^{1}$

\section{d. Aspergilose}

É a segunda infecção fúngica oportunística mais freqüente em imunossuprimidos. A espécie mais comum é o Aspegillus fumigatus, mas o Aspegillus flavus é o mais encontrado nas lesões cutâneas primárias. As infecções cutâneas primárias ocorrem em torno do orifício de cateteres ou incisões. ${ }^{2}$ Manifestam-se como celulites, pápulas ou placas eritematosas, exantemas máculo-papulosos similares aos causados por drogas, ou lesões pustulosas e necróticas de difícil diagnóstico diferencial., ${ }^{1,10}$

\section{e. Criptococose}

Ocorre, em geral, após o $6^{\circ}$ mês do transplante. Cerca de $10 \%$ dos pacientes têm formas disseminadas da doença com lesões cutâneas morfologicamente muito variáveis, como pápulas, pústulas, placas, paniculites, áreas edematosas, abscessos e ulcerações. ${ }^{10,11}$

\section{d. Histoplasmose}

A infecção cutânea pelo Histoplasma capsulatum é comum nos transplantados e provoca lesões diversas como ulcerações, pústulas, pápulas, nódulos, vegetações, púrpuras, paniculites e abscessos. As formas tegumentares mais freqüentes ocorrem em mucosas como ulcerações na boca, língua e faringe. Quando a infecção é generalizada, o eritema nodoso é comum..$^{10,11}$

\section{e. Feohifomicose}

Determina lesões nódulo-císticas inflamatórias em áreas expostas, com freqüência após trauma local com retenção de corpo estranho. Quando há comprometimento sistêmico ele é predominantemente neurológico. ${ }^{10,11}$

\section{Infecções Virais}

a. Infecções herpéticas: o Herpesvirus hominis (HV) tem tendência à maior ativação e replicação em pacientes com imunossupressão iatrogênica. Por conseqüência, as lesões são mais graves e extensas e o tempo de evolução e cura é mais demorado. É comum ocorrer ulceração, necrose e os surtos serem subentrantes. ${ }^{1}$ Conforme 
literatura, 4,8\% das crianças transplantadas renais apresentaram episódios de herpes simples e $2,8 \%$, de herpes zoster. ${ }^{2}$ Normalmente, as lesões são muito dolorosas e, no caso do Herpes zoster, há maior tendência à nevralgia pós-herpética. ${ }^{1,2}$ No transplantado renal apresentado, evidenciou-se um zoster generalizado.(fig.1).

\section{b. Infecções pelo Vírus Papiloma Humano (HPV)}

Caracteriza-se pela maior extensão e persistência das lesões em relação aos imunocompetentes. A ocorrência de verruga vulgar é comum chegando a $53 \%$ de acometimento. ${ }^{1,2}$

\section{c. Molusco contagioso}

Aproximadamente $7 \%$ dos transplantados pediátricos apresentam lesões de molusco contagioso. ${ }^{2}$ As manifestações clínicas são típicas, porém são mais numerosas e freqüentes em locais atípicos como na face e genitais. ${ }^{2,1}$

\section{d. Citomegalovirose (CMV)}

É a virose oportunística mais freqüente nos transplantados (10 a $20 \%) .{ }^{2}$ Cerca de $80 \%$ das infecções ocorrem após a $2^{\mathrm{a}}$ semana do transplante. As lesões variam desde exantemas e máculas isoladas até petéquias e ulcerações, principalmente nas mucosas ${ }^{1,2} \mathrm{O}$ prognóstico dos pacientes com CMV cutânea é ruim, pois quase sempre há envolvimento sistêmico. ${ }^{13}$

\section{Infecções Bacterianas}

\section{a. Bactérias Gram-positivas}

As infecções bacterianas mais encontradas nos transplantados são as estrepto e estafilococcias. ${ }^{1}$ Elas tendem a ter maior gravidade e apresentar quadros atípicos como celulites por estreptococos apenas com edema e foliculites somente com crostas. ${ }^{1,2}$

\section{b. Bactérias Gram-negativas}

A Pseudomonas é o patógeno com maior potencial de produzir infecções graves. ${ }^{1,2}$ As septicemias estão associadas, em 10\% dos casos, com lesões cutâneas e o ectima gangrenoso é a expressão mais clássica. ${ }^{1}$ Outras manifestações são: as vesículas, foliculites, nódulos subcutâneos, celulite, petéquias e púrpuras. ${ }^{13}$

\section{c. Micobacterioses}

São representadas mais comumente pelo complexo Mycobacterium avium intracellulare. ${ }^{10,13}$ As lesões variam podendo localizar-se na pele e subcutâneo através de pápulas, nódulos, lesões úlcerocrostosas e verrucosas., ${ }^{1,2}$

\section{Infecções Parasitárias}

São encontrados casos típicos de escabiose e pediculose nos transplantados, porém com expressões mais exuberantes. A escabiose crostosa é mais freqüente nos transplantados devido à imunossupressão e caracteriza-se por lesões espessas e crostosas, placas cinzas ou amareladas em localizações típicas da escabiose ou disseminadas. Possui grande infecciosidade e o prurido é variável. ${ }^{1,13}$

\section{5) Tumores cutâneos}

Indivíduos imunossuprimidos, particularmente os transplantados, desenvolvem tumores cutâneos benignos e malignos com maior freqüência do que a população normal. Há um aumento de até $40 \%$ de lesões benignas e pré-malignas. ${ }^{14,15} \mathrm{O}$ tumor maligno que mais acomete as crianças transplantadas é o linfoma ( $50 \%$ dos tumores), seguido pelas neoplasias cutâneas $(20 \%) .{ }^{1,15} \mathrm{O}$ câncer de pele mais comum nos transplantados pediátricos é o carcinoma epidermóide (73,5\% dos tumores), seguido pelo melanoma (15\% dos tumores e 5,5 vezes mais freqüente do que na população em geral) $\cdot{ }^{14,15} \mathrm{Em}$ estudo comparativo sobre a incidência de tumores cutâneos malignos entre transplantados e imunocompetentes, a incidência de tumores foi de $43 \%$ versus $4 \%$, respectivamente. Entre os fatores envolvidos na predisposição aumentada às neoplasia cutâneas estão: a radiação ultravioleta, imunossupressores e seu efeito cumulativo, fototipos baixos, exposições solares agudas durante a infância e tempo de residência em climas quentes antes do transplante. A formação precoce de tumores é favorecida por vários mecanismos. Entre eles estão a diminuição da vigilância imunológica, o efeito de vírus oncogênicos como algumas cepas do HPV e o uso cada vez maior de drogas como a ciclosporina, tacrolimus e azatioprina que, sabidamente, aumentam a chance de neoplasias por ação autônoma. ${ }^{14} \mathrm{O}$ aparecimento de tumores depende do tempo de imunossupressão e a maioria deles ocorrem ao redor dos 10 anos pós-transplante. As neoplasias tendem a desenvolver-se mais precocemente e com expressão mais agressiva do que nos indivíduos imunocompetentes, podendo levar a um aumento de 5 a $8 \%$ na mortalidade dos transplantados. ${ }^{14,15}$

\section{SUMMARY}

Introduction: Organ transplant is an example of the great progression achieved by the current medicine, along with its benefits and problems concerning to this advance. Many of these consequences have important cutaneous manifestations which should be known and studied. Methods: The authors present three clinical cases of pediatric transplant - bone marrow, liver and kidney - with its dermatological manifestations observed within the first six months post transplant. Further, a review of the literature on dermatological manifestations in pediatric transplant is carried through. Conclusions: Face to the increasing number of transplant patients and their life perspectives, a large number of cutaneous diseases in this group is found. Controversially, there is a little literary subsidy concerning dermatological manifestations in pediatric transplant. For this reason, we should have better knowledge of the great variety of disorders to provide an adequate prevention and therapeutic guidance to the pediatric transplant patient.

Key words: Skin, Transplant, Children, Drugs eruption, Skin cancer, Graft-versus-host-disease, Infections. 


\section{REFERÊNCIAS}

1. Blauvelt A. Mucocutaneous manifestation of the non-HIV-infected imunossupressed host. In Freedberg IM, Eisen AZ, Wolff K, Austen KF, Goldsmith LA, Katz SI (eds), 6a ed, Dermatology in General Medicine, New York: McGraw-Hill 2003: 1152-64.

2. Euvrard S, Kanitakis J, Cochat P, Cambazard F, Claudy A. Skin diseases in children with organ transplants. J Am Acad Dermatol 2001; 44: 932-9.

3. Rose BD. Up to Date version 12.2 CD Room. 2004 [online] http://uptodate.com

4. Litt JZ. Drug Eruption Reference Manual. New York: The Partenon Publishing Group, 2001: 441p.

5. Armitage JO. Bone marrow transplantation. N Engl J Med 1994; 330: 827-38.

6. Porock D. Factors influencing the severity of radiation skin and oral mucosal reactions: development of a conceptual framework. Eur J Cancer Care 2002; 11: 33-43.

7. Susser WS, Whitaker-Worth DL, Grant-Kels JM. Mucocutaneous reactions to chemoterapy. J Am Acad Dermatol 1999; 40: 367-98.

8. Johnson ML, Farmer ER. Graft-versus-host reactions in dermatology. J Am Dermatol 1998; 38: 369-92.
9. Horn TD. Graft versus host disease In Freedberg IM, Eisen AZ, Wolff K, Austen KF, Goldsmith LA, Katz SI (eds) $6^{\text {a }}$ ed, Dermatology in General Medicine, New York (USA): McGraw-Hill 2003: 1144-52.

10. Hogewoning AA, Goettsch W, van Loveren H, de Fijter JW, Vermeer BJ, Bouwes Baviinck JN. Skin infections in renal transplant recipients. Clin Transplant 2001; 15: $32-8$.

11. Marques S. Micoses em imunodeprimidos. In. Zaitz C. Compêndio de micologia médica. Rio de Janeiro: Editora Médica e Científica, 1998: 325-46.

12. Vettorato G, Carvalho AVE, Lecompte SM, Trez EG, Garcia VD, Keitel E. Freqüência de dermatoses infecciosas em 208 pacientes transplantados renais. An Bras Dermatol 2003; 78: 283-8.

13. Snydman DR. Infection in solid organ transplantation. Transpl Inf Dis 1999; 1: 21-28

14. Euvrard S, Kanitakis J, Cochat P e Claudy A. Skin Cancer following Pediatric Organ Transplantation. Dermatol Surg 2004:30:616-21.

15. Euvrard S, Kanitakis J, Claudy A. Skin cancer after organ transplantation. N Engl J Med 2003; 348: 1681-91. 


\section{NORMAS DE PUBLICAÇÃO}

O JBT - Jornal Brasileiro de Transplantes, ISSN 1678-3387, órgão oficial da ABTO - Associação Brasileira de Transplante de Órgãos, destina-se à publicação de artigos da área de transplante e especialidades afins, escritos em português, inglês ou espanhol.

Os manuscritos submetidos à Revista, que atenderem às "Instruções aos Autores" e estiverem de acordo com a política Editorial da Revista, após aprovação pelo Conselho Editorial, serão encaminhados para análise e avaliação de dois revisores, sendo o anonimato garantido em todo o processo de julgamento. Os comentários serão devolvidos aos autores para as modificações no texto ou justificativas de sua conservação. Somente após aprovação final dos editores e revisores, os trabalhos serão encaminhados para publicação. Serão aceitos Artigos Originais, Artigos de Revisão, Apresentação de Casos Clínicos, Cartas ao Editor, Ciências Básicas Aplicadas aos Transplantes, Opinião Técnica, Prós e Contras, Imagem em Transplante e Literatura Médica e Transplantes.

\section{ARTIGOS ORIGINAIS}

São trabalhos destinados à divulgação de resultados da pesquisa científica. Devem ser originais e inéditos. Sua estrutura deverá conter os seguintes itens: Resumo, Introdução, Métodos, Resultados, Discussão, Conclusão e Referências e Abstract. Devem ter, no máximo, 35 referências.

\section{ARTIGOS DE REVISÃO}

Constituem da avaliação crítica e sistemática da literatura sobre um assunto específico, podendo ser: Revisão Acadêmica, Revisão de Casos, Revisões Sistemáticas, etc. O texto deve esclarecer os procedimentos adotados na revisão, a delimitação e os limites do tema, apresentar conclusões e ou recomendações e ter, no máximo, 50 referências.

\section{APRESENTAÇÃO DE CASOS CLÍNICOS}

Relata casos de uma determinada doença, descrevendo seus aspectos, história, condutas, etc... incluindo breve revisão da literatura, com 15 referências, no máximo.

\section{CARTAS AO EDITOR}

Tem por objetivo discutir trabalhos publicados na revista ou relatar pesquisas originais em andamento. Devem ter, no máximo, três laudas e cinco referências.

\section{CIÊNCIAS BÁSICAS APLICADAS AOS TRANSPLANTES}

Artigos de revisão sobre temas de ciência básica, cujo conhecimento tem repercussão clínica relevante para Transplantes. Devem ter, no máximo, dez laudas e 15 referências e serão feitas apenas a convite do JBT.

\section{OPINIÃO TÉCNICA}

Destina-se a publicar uma resposta a uma pergunta de cunho prático através de opinião de um especialista (Quem? Quando? Como? Onde? Por quê?). Devem ter, no máximo, seis laudas e apresentarem três referências.

\section{PRÓS E CONTRAS}

Frente a uma questão, dois autores serão escolhidos pela editoria do JBT, para discutirem os aspectos positivos e os negativos de um assunto controvertido. São dois autores, um escrevendo a favor e o outro contra uma determinada proposição. Cada autor deve escrever no máximo três laudas e cinco referências.

\section{IMAGEM EM TRANSPLANTE}

Uma imagem relacionada a Transplante, patognomônica, típica, de US, RX, CT, RNM, foto de cirurgia, microscopia, sinal clínico, etc., seguida de um texto curto, explicativo, de, no máximo, 15 linhas e três referências.

\section{LITERATURA MÉDICA E TRANSPLANTES}

Um artigo original de qualquer área médica, incluindo transplantes, que seja importante para o conhecimento do médico transplantador, poderá ser revisado, e o resumo do trabalho original será publicado, seguido de um pequeno resumo comentado ressaltando sua importância. O resumo deve ter até duas laudas e apresentar a referência completa do trabalho. Autores serão convidados para esse tipo de publicação, mas poderão ser considerados para publicação no JBT trabalhos enviados sem convites quando considerados relevantes pelos editores.

As normas que se seguem, devem ser obedecidas para todos os tipos de trabalhos e foram baseadas no formato proposto pelo International Committee of Medical Journal Editors e publicado no artigo: Uniform requirements for manuscripts submitted to biomedical journals. Ann Intern Med 1997;126;36-47, e atualizado em outubro de 2001. Disponível no endereço eletrônico: http://www.icmje.org

Obs.: Uma lauda $=2.800$ toques (incluindo espaços), formato Word for Windows, A4, cp.12, espaço 1,5.

\section{NORMAS PARA ELABORACÃO DO MANUSCRITO}

\section{Requisitos técnicos}

a) O trabalho deverá ser digitado em espaço duplo, fonte Arial tamanho 12, margem de $2,5 \mathrm{~cm}$ de cada lado, com páginas numeradas em algarismos arábicos, iniciando cada seção em uma nova página, na seqüência: página de título, resumo e descritores, texto, agradecimentos, referências, tabelas e legendas. Se impresso, deverão ser enviadas duas cópias, em papel tamanho ISO A4 (210x297mm), mais uma cópia digital (disquete ou CD-ROM)

b) Permissão à ABTO para reprodução do material;

c) Aprovação de um Comitê de Ética da Instituição onde foi realizado o trabalho, quando referente a trabalhos de pesquisa envolvendo seres humanos.

d) Declaração que o manuscrito não foi submetido a outro periódico, contendo assinatura de todos os autores.

e) Conflitos de interesse de cada autor.

Após as correções sugeridas pelos revisores, a forma definitiva do trabalho deverá ser encaminhada por e-mail ou, se impresso, em duas vias, com cópia em disquete $3 \frac{1}{2}$ ou em CD-ROM. Os originais não serão devolvidos.

Somente o JBT-Jornal Brasileiro de Transplantes poderá autorizar a reprodução em outro periódico, dos artigos nele contidos.

O Corpo Editorial poderá aceitar a publicação de trabalhos de outra natureza ou escritos em outra língua.

\section{PREPARO DO MANUSCRITO}

A página inicial deve conter:

a) Título do artigo, em português (ou espanhol) e inglês, sem abreviaturas; que deverá ser conciso, porém informativo;

b) Nome completo de cada autor, com o seu grau acadêmico e afiliação institucional;

c) Nome do departamento e instituição aos quais o trabalho deve ser atribuído;

d) Nome, endereço completo, fax e e-mail do autor responsável e a quem deve ser encaminhada correspondência;

e) fontes de auxílio à pesquisa, se houver. 


\section{RESUMO E ABSTRACT}

Para os artigos originais, os resumos devem ser apresentados no formato estruturado, com até 250 palavras destacando: os objetivos, métodos, resultados e conclusões. Para as demais seções, o resumo pode ser informativo, porém devendo destacar o objetivo, os métodos usados para levantamento das fontes de dados, os critérios de seleção dos trabalhos incluídos, os aspectos mais importantes discutidos, as conclusões e suas aplicações. Abreviaturas devem ser evitadas. Abaixo do resumo e abstract, especificar no mínimo 5 e no máximo 10 descritores (keywords) que definam o assunto do trabalho. Os descritores deverão ser baseados no DeCS (Descritores em Ciências da Saúde) publicado pela Bireme que é uma tradução do MeSH (Medical Subject Headings) da National Library of Medicine e disponível no endereço eletrônico: http://decs.bvs.br. Os resumos em português e inglês deverão estar em páginas separadas.

\section{TEXTO}

Iniciando em nova página, o texto deverá obedecer à estrutura exigida para cada tipo de trabalho. A citação dos autores no texto deverá ser numérica e seqüencial, utilizando algarismos arábicos, sobrescritos, após a pontuação e sem parênteses. Os nomes dos autores não deverão ser citados no texto; apenas a indicação numérica e seqüencial, correspondente à referência.

\section{AGRADECIMENTOS}

Após o texto, em nova página, indicar os agradecimentos às pessoas ou instituições que prestaram colaboração intelectual, auxílio técnico e ou de fomento, e que não figuraram como autor.

\section{REFERÊNCIAS}

Devem ser numeradas consecutivamente, na mesma ordem em que foram citadas no texto e identificadas com números arábicos. A apresentação deverá estar baseada no formato denominado "Vancouver Style", conforme exemplos abaixo, e os títulos de periódicos deverão ser abreviados de acordo com o estilo apresentado pela List of Journal Indexed in Index Medicus, da National Library of Medicine e disponibilizados no endereço:

http://www.ncbi.nlm.nih.gov/entrez/linkout/journals/jourlists.cgi?typeid=1\&t ype $=$ journals \&operation $=$ Show

Para todas as referências, cite todos os autores até seis. Acima de seis, cite os seis primeiros, seguidos da expressão et al.

\section{ARTIGOS DE PERIÓDICOS}

Donckier V, Loi P, Closset J, Nagy N, Quertinmont E, Lê Moine O, et al. Preconditioning of donors with interleukin-10 reduces hepatic ischemia-reperfusion injury after liver transplantation in pigs. Transplantation 2003; 75:902-4.

Papini H, Santana R, Ajzen, H, Ramos, OL, Pestana, JOM. Alterações metabólicas e nutricionais e orientação dietética para pacientes submetidos a transplante renal. J Bras Nefrol 1996;18:356-68.

\section{RESUMOS PUBLICADOS EM PERIÓDICOS}

Raia S, Massarollo PCP, Baia CESB, Fernandes AONG, Lallee MP, Bittencourt $\mathrm{P}$ et al. Transplante de fígado "repique": receptores que também são doadores [resumo]. JBT J Bras Transpl 1998;1:222.

\section{LIVROS}

Gayotto LCC, Alves VAF. Doenças do fígado e das vias biliares. São Paulo: Atheneu; 2001.

\section{CAPÍTULOS DE LIVROS}

Raia S, Massarollo PCB. Doação de órgãos. In: Gayotto LCC, Alves VAF. Doenças do fígado e das vias biliares. São Paulo: Atheneu; 2001. p.1113-20.

\section{TRABALHOS APRESENTADOS EM EVENTOS}

Sokal EM, Cleghorn G, Goulet O, Da Silveira TR, McDiarmid S, Whitington P. Liver and intestinal transplantation in children: Working Group Report [Presented at $1^{\circ}$.World Congress of Pediatric Gastroenterology, Hepatology and Nutrition]. J Pediatr Gastroenterol Nutr 2002; 35 Suppl 2:S159-72.

\section{TESES}

Couto WJ, Transplante cardíaco e infecção [tese]. São Paulo:Universidade Federal de São Paulo; 2000.

Pestana JOM. Análise de ensaios terapêuticos que convergem para a individualização da imunossupressão no transplante renal [tese]. São Paulo: Universidade Federal de São Paulo; 2001.

\section{DOCUMENTOS ELETRÔNICOS}

Matsuyama M, Yoshimura R, Akioka K, Okamoto M, Ushigome H, Kadotani $\mathrm{Y}$, et al. Tissue factor antisense oligonucleotides prevent renal ischemia reperfusion injury. Transplantation [serial online] 2003 [cited 2003 Aug 25];76:786-91. Available from: URL: http://gateway2.ovid.com/ovidweb.cgi.

Obs: Dados não publicados, comunicações pessoais, deverão constar apenas em "notas de rodapé". Trabalhos enviados para a revista devem ser citados como trabalhos no "prelo", desde que tenham sido aceitos para publicação. Deverão constar na lista de Referências, com a informação: [no prelo] no final da referência, ou [in press] se a referência for internacional.

\section{TABELAS, FIGURAS, LEGENDAS E ABREVIATURAS Tabelas}

Devem ser confeccionadas com espaço duplo. A numeração deve ser seqüencial em algarismos arábicos, na ordem que foram citadas no texto. Devem ter título, sem abreviatura, e cabeçalho para todas as colunas. No rodapé da tabela deve constar legenda para abreviaturas e testes estatísticos utilizados. Não devem conter linhas verticais. Legendas devem ser acompanhadas de seu significado. Somente duas tabelas deverão ser enviadas.

\section{Figuras (gráficos, fotografias, ilustrações)}

As figuras devem ser apresentadas em papel brilhante, tamanho não superior a $203 \times 254 \mathrm{~mm}$, contendo no verso, em uma etiqueta, sua numeração, conforme citada no manuscrito e uma seta indicando sua posição. Quando gravadas em disquete ou CD-ROM, deverão estar no formato JPG ou TIF, com resolução de 300dpi. Somente duas figuras, em preto e branco, deverão ser enviadas para publicação. Ilustrações extraídas de outras publicações deverão vir acompanhadas de autorização por escrito do autor/editor, constando na legenda da ilustração a fonte de onde foi publicada.

\section{Legendas}

Imprimir as legendas para as ilustrações usando espaço duplo, uma em cada página separada. Cada legenda deve ser numerada em algarismos arábicos, correspondendo a cada ilustração e na ordem que foram citadas no trabalho.

Abreviaturas e Siglas: Devem ser precedidas do nome completo quando citadas pela primeira vez. Nas legendas das tabelas e figuras devem ser acompanhadas de seu significado. Não devem ser usadas no título e no resumo.

\section{ENVIO DO MANUSCRITO}

Os trabalhos devem ser enviados para: e-mail: abto@abto.org.br

ou

Jornal Brasileiro de Transplantes - JBT

A/C Dr. Mário Abbud Filho

Av. Paulista, 2001, $17^{\circ}$ andar - Cj. 1704/1707

CEP 01311-300 - São Paulo - SP

Telefax.: (11) 3283-1753 